[Short Communication]

\section{The first description of the male of Cybaeus zenifukiensis (Araneae: Cybaeidae)}

\author{
Naoki Koike
}

\author{
Department of Zoology, Graduate School of Science, \\ Kyoto University, Kyoto 606-8502, Japan \\ E-mail:koike@zoo.zool.kyoto-u.ac.jp
}

\begin{abstract}
The male of Cybaeus zenifukiensis (Komatsu 1968) is described and illustrated for the first time. Intraspecific variation is also noted using topotypic specimens.
\end{abstract}

Key words - Cybaeus zenifukiensis, Heterocybaeus, Japan, male, taxonomy, variation

\section{Introduction}

Cybaeus zenifukiensis was originally described under the genus Heterocybaeus (Komatsu 1968) on the basis of a single female specimen, and there were no other records of this species. Though all Heterocybaeus species were described with only female specimens and no male has been described (Ihara 2009a), Heterocybaeus was synonymized with Cybaeus (Ihara 2009b).

I did a survey in the type locality cave and collected many females of Cybaeus zenifukiensis and undescribed males. I judge these males to be the males of Cybaeus zenifukiensis, and will describe the male for the first time and note its variation in this paper.

\section{Materials and methods}

All specimens were collected from the type locality. Altitude and coordinates for the type locality were obtained using a Garmin eTrex GPS unit. Specimens were preserved in $75 \%$ ethanol, and were examined and drawn under a stereoscopic microscope (Leica M125) with a drawing tube and an ocular micrometer.

Terminology mainly follows Ubick et al. (2005), that of the male genital structure follows Copley et al. (2009), and that of leg spines follows Komatsu (1968).

The abbreviations used in this paper are as follows: ALE, anterior lateral eye; AME, anterior median eye; PLE, posterior lateral eye; PME, posterior median eye; PLS, prolateral spine; PVS, proventral spine; RLS, retolateral spine; RVS, retroventral spine; VS, ventral spine.

Eye size means length of the long axis of the eye. All measurements are given in $\mathrm{mm}$.

The specimen used for male description will be deposited in the National Museum of Nature and Science, Tokyo
(NSMT). The other specimens will be deposited in the Zoological Collection of Kyoto University Museum (KUZ).

\section{Description}

Cybaeus zenifukiensis (Komatsu 1968)

[Japanese name: Zenifuki-namihagumo]

(Figs. 1-3)

Heterocybaeus zenifukiensis Komatsu 1968, p.15, figs. 20, 36, 52, 68, 89 [female holotype missing, not examined].

Specimen examined for male description. 1ð, Zenifukiana cave, Akka, Iwaizumi-cho, Simohei-gun, Iwate Prefecture, Japan (alt. 470 m, 40 $00^{\prime} 01^{\prime \prime} \mathrm{N}, 141^{\circ} 42^{\prime} 09^{\prime \prime} \mathrm{E}$ ), 8-IX-2010, Naoki Koike leg. (NSMT-Ar 9789)

Measurements: Body length 5.13. Carapace length 2.81; width 2.09. Abdomen length 2.63; width 2.03. Labium length 0.38 ; width 0.45 . Sternum length 1.34 ; width 1.13 . Eye sizes: AME 0.08; ALE 0,13; PME 0.12; PLE 0.12. Distances between eyes: AME-AME 0.09; AME-ALE 0.05; ALE-PLE 0.06; PME-PLE 0.11; PME-PME 0.13. Anterior eye row width 0.58 ; posterior eye row width 0.78 . Ocular area length 0.30 . Clypeus height 0.18 . Length of legs [total length (femur + patella + tibia + metatarsus + tarsus $)]:$ I 9.64 $(2.45+0.90+2.42+2.36+1.51)$, II $9.06 \quad(2.38+0.91+$ $2.13+2.18+1.46)$, III $8.17(2.16+0.90+1.71+2.13+$ 1.27), IV $9.98(2.56+0.83+2.35+2.67+1.57)$. Length of palp [total length (femur + patella + tibia + cymbium $)$ ]: 3.35 $(1.19+0.49+0.47+1.20)$

Cephalothorax: Carapace longer than wide (length/width 1.34), with some short hairs on radial furrows sparsely, median furrow distinct. Eyes distinct, eight in number, ALE largest, AME smallest. Anterior eye row straight as seen from front, recurved as seen from above; posterior eye row procurved as seen from front, weakly recurved as seen from above. Chelicerae developed and furnished with 3 promarginal cheliceral teeth and 11 retromarginal cheliceral teeth. Labium wider than long (length/width 0.84). Sternum with some hairs sparsely, longer than wide (length/width 1.19).

Legs: All tarsi with 6 trichobothria in single dorsal row increasing in length distally. Tibia I with 3PVS (1-3), 3PLS $(1,3,4)$, 3RVS $(1-3)$. Metatarsus I with 3PVS (1-3), 1PLS (2), 3 RVS (1-3), 1RLS (1). Tibia II with 3PVS (1-3), 4PLS (1-4), 4RVS (1-4). Metatarsus II with 3PVS (1-3), 4PLS (1-4), 3RVS (1-3), 1RLS (1) and VS. Leg formula IV-I-II-III.

Male palp (Figs. 1-3): Embolus long and narrow. Posterior arm of tegular apophysis with sickle-shaped, prolaterally directed tip (Fig. 1). Tibia short, swollen dorsally, dented retroventrally, and retrolateral tibial apophysis nearly as long as tibia (Fig. 2). Retrolateral patellar apophysis relatively short, furnished with 14 peg setae (Fig. 3).

Abdomen: Ovate, longer than wide, covered with hairs. Colulus degenerated into 2 setae. Anterior spinnerets larger than posterior ones. 


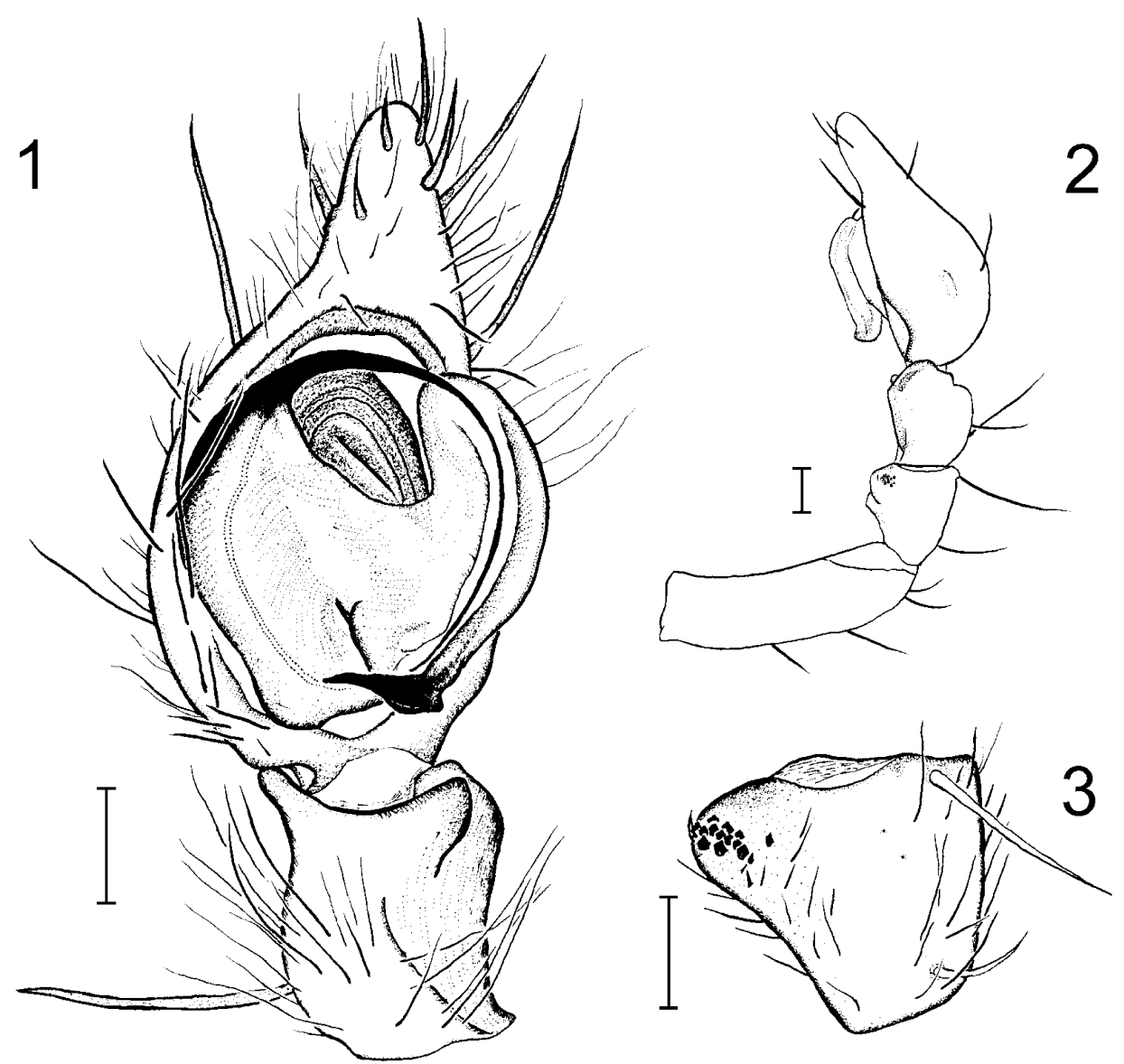

Figs. 1-3. Cybaeus zenifukiensis (Komatsu 1968), male, left palp (NSMT-Ar 9789, Zenifuki-ana cave, Iwate Pref.). 1. Ventral; 2. Retrolateral; 3. Patella, dorsal. Scales $=0.2 \mathrm{~mm}$.

Coloration and markings: Carapace and legs brownish yellow, blackened around eyes. Chelicerae yellowish brown, fangs darker. Maxillae light yellowish brown, tips white. Labium same color as maxillae, sternum lighter. Abdomen whitish grey with reddish brown hairs, without distinct markings.

Remarks. Male palp of this species resembles that of Cybaeus tetricus (C.L. Koch, 1839), the type species of Cybaeus, but can be easily distinguished from the latter by the shape of the posterior arm of the tegular apophysis.

Distribution. Only known from its type locality.

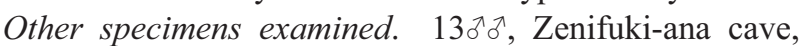
Akka, Iwaizumi-cho, Simohei-gun, Iwate Prefecture, Japan (alt. $470 \mathrm{~m}, 40^{\circ} 00^{\prime} 01^{\prime \prime} \mathrm{N}, 141^{\circ} 42^{\prime} 09^{\prime \prime} \mathrm{E}$ ), 8-IX-2010, Naoki Koike leg.

Variation of males $(\mathrm{n}=14)$. Measurements: Body length 5.09-6.56. Carapace length 2.73-3.16; carapace width 2.02-2.26. Sternum length $1.30^{-} 1.46$; sternum width $1.13^{-}$ 1.33. Numbers of peg setae on retrolateral patellar apophysis: 13-24. Almost all specimens have different numbers of peg setae, comparing their left palps with their right ones.

\section{Acknowledgements}

The author is most grateful to Professor Takahide Kamura, Otemon Gakuin University, for his advice on illustration. I also express my hearty thanks to Dr. Makoto Yoshida and Mr. Takafumi Nakano for allowing me to use their microscopes, without which this paper could not have been completed. This work supported in part by Global COE program A06 of Kyoto University.

\section{References}

Copley, C. R., Bennett, R. \& Perlman, S. J. 2009. Systematics of Nearctic Cybaeus (Araneae: Cybaeidae). Invertebrate. Systematics, 23: $367-401$.

Ihara, Y. 2009a. Cybaeidae. pp. 152-168. In: Ono, H. (ed.), The spiders of Japan, with Keys to the Families and Genera and Illustrations of Species. Tokai University Press, Kanagawa, $\mathrm{xvi}+739$ pp. (In Japanese)

Ihara, Y. 2009b. Revision of the Cybaeus hiroshimaensis-group (Araneae: Cybaeidae) in western Japan. Acta Arachnol., 58: 69-85.

Komatsu, T. 1968. Cave spiders of Japan. II. Cybaeus, Dolichocybaeus and Heterocybaeus (Cybaeinae). Arachnological Society of East Asia, Osaka, 38 pp.

Ubick, D., Paquin, P., Cushing, P. E., \& Roth, V. (eds.) 2005. Spiders of North America: an identification manual. American Arachnological Society, Keene (New Hampshire), 377 pp. 